\title{
Os reveses do escândalo político-midiático nas eleições presidenciais de 2014
}

THE SETBACKS OF THE POLITICAL AND MEDIAGENIC SCANDAL IN THE BRAZILIAN 2014 PRESIDENTIAL ELECTIONS

\section{Carla Montuori Fernandes}

Doutora e pós-doutora em Ciências Sociais pela Pontifícia Universidade Católica de São Paulo (PUC-SP). Docente do Programa de Pós-Graduação em Comunicação e Cultura das Mídias pela Universidade Paulista (UNIP) e do Centro Universitário Assunção (UNIFAI). Pesquisadora do Núcleo de Estudos em Arte, Mídia e Política da PUC-SP.

E-mail: carla_montuori@ig.com.br

Recebido em 3 de fevereiro de 2015. Aprovado em 25 de junho de 2015.

\section{Resumo}

O escândalo político na democracia contemporânea está atrelado aos conceitos de transgressão e midiatização. $\mathrm{O}$ ato de romper com normas legais ou com sistemas de valores de uma sociedade e a veiculação dos acontecimentos em esfera global consolidam o escândalo político-midiático. Nas eleições de 2014, as denúncias de um esquema de corrupção envolvendo a Petrobras mobilizaram atores políticos, sobretudo a presidente Dilma Rousseff (PT), que disputava o segundo mandato presidencial. Nesse sentido, o artigo tem por objetivo estudar o enquadramento do escândalo político da Petrobras no Jornal Nacional durante o período da campanha eleitoral.

Palavras-chave: Jornalismo. Escândalo político-midiático. Jornal Nacional.

1 Versão revista do trabalho apresentado no XII Congreso Latinoamericano de Investigadores de la Comunicación - Alaic, realizado na Facultad de Ciencias y Artes de la Comunicación, Lima, Peru, de 6 a 8 de agosto de 2014

2 Pesquisa financiada pelo CAEPM - Centro de Altos Estudos da ESPM. 


\section{Abstract}

The political scandal in contemporary democracy is linked to the concepts of transgression and mediatization. The act of breaking rules legally protected or systems of values of a society and the reporting of public events in the global level consolidate the basis of the political and mediagenic scandal. In the Brazilian 2014 presidential elections, allegations of a corruption scheme involving Petrobras mobilized political actors, especially President Dilma Rousseff (PT), who disputed the second presidential term. Therefore, the paper aims to study the framework of the political scandal of Petrobras in the Jornal Nacional news program during the election campaign.

Keywords: Journalism. Media related political scandal. Jornal Nacional.

\section{Introdução}

A campanha eleitoral para escolha do presidente do Brasil, no ano 2014, reproduziu uma das conjunturas eleitorais mais turbulentas, desde o período de redemocratização, após 21 anos de ditadura militar (1964-1985). A campanha pela reeleição da presidente Dilma Rousseff (PT), em um cenário de crise política, inflamou o discurso da oposição e da opinião pública em torno de mudanças.

As manifestações sociais que ocorreram em junho de 2013, alavancadas inicialmente para questionar o aumento das passagens de transporte público em diversos estados brasileiros, ganharam adesão nacional, com reivindicações populares que passaram a aclamar por melhorias nas prestações dos serviços públicos e se estenderam à cobrança de ética na política.

Diante das inúmeras ondas de protestos, no final do mês de junho, a popularidade da presidente Dilma Rousseff (PT) despencou de 57\% para 30\%, com aumento da reprovação do governo de $9 \%$ para $25 \%$ dos entrevistados (FOLHA DE S. PAULO, 2013). Aliado ao fato de que a disputa política, segundo esclarece Gomes (2004), transformou-se em um espaço de competição pela produção e imposição de uma percepção de imagem pública positiva dos atores políticos, a reeleição da candidata Dilma já indicava infortúnios um ano antes da corrida presidencial.

No âmbito partidário, o Partido da Social Democracia Brasileira (PSDB), maior partido de oposição ao governo, que polarizou como o Partido dos Trabalhadores (PT) as últimas seis eleições presidenciais, vislumbrava na figura do candidato Aécio Neves (PSDB) a possibilidade de retornar ao poder. Não obstante, o Partido Socialista Brasileiro (PSB), forte aliado do PT, que disputou ao lado do ex-presidente Luiz Inácio Lula da 
Silva e da presidente Dilma Rousseff as eleições presidenciais de 2002, 2006 e 2010, rompia a aliança partidária e lançava a candidatura de Eduardo Campos (PSB) à presidência do país.

A par dos desajustes econômicos e partidários, um escândalo político-midiático agitava o cenário eleitoral já durante a campanha. Denúncias de desvios de verbas, fraudes e transações ilícitas envolviam a Empresa Brasileira de Petróleo (Petrobras), uma das maiores petrolíferas de capital aberto do mundo. Entre os citados no escândalo, estavam os executivos de alto escalão do governo federal, políticos e partidos da base governista da presidente Dilma Rousseff (PT). Ao ocupar o cargo mais alto do poder executivo, as denúncias recaíam sobre o governo Dilma, com probabilidade de impactar a imagem da candidata à reeleição.

Thompson (2002) esclarece que os acontecimentos representados pela mídia sob a forma de escândalos midiáticos geralmente se mostram avassaladores para os indivíduos que se encontram no centro do evento, sobretudo pelo tempo e energia despendidos para administrar um processo que, por vezes, se mostra incontrolável. Nesse sentido, o escândalo pode atuar no esvaziamento do capital simbólico de qualquer ator político. Capital supremamente útil, tal qual elucidou Bourdieu (1998, p. 188-9), que

só pode ser conservado mediante o trabalho constante que é necessário não só para acumular o crédito como também para evitar o descrédito: daí toda a prudência, todos os silêncios, todas as dissimulações, impostos a personagens públicas incessantemente colocadas perante o tribunal da opinião, pela preocupação constante de nada dizer ou fazer que possa ser lembrado pelos adversários.

O escândalo midiático veiculado durante o período de campanha eleitoral tornava a possibilidade de reeleição de Dilma Rousseff (PT) no primeiro turno mais distante a cada nova pesquisa. Entretanto, a corrida presidencial de 2014 ensejou novos rumos com a morte de Eduardo Campos (PSB). Desde a oficialização das candidaturas, em 6 de julho de 2014, o cenário da campanha veiculado por diversos órgãos de pesquisa, como Instituto Brasileiro de Opinião Pública e Estatística (IBOPE), Datafolha e outros, mostrava uma polarização em torno da presidente e candidata à reeleição Dilma Rousseff (PT) e do candidato Aécio Neves (PSDB).

A candidata do PT aparecia nas pesquisas com aproximadamente $36 \%$ das intenções de voto, seguida de $20 \%$ do segundo colocado, o candidato Aécio Neves. O candidato Eduardo Campos (PSB) estava na terceira colocação e oscilava entre 6\% e 8\% na preferência do eleitorado (DATAFOLHA, 2014). Em quase todos os cenários previstos pelos institutos, Dilma Rousseff (PT) se reelegeria no segundo turno. 
A morte precoce de Eduardo Campos (PSB), no dia 13 de agosto, em um acidente aéreo, quando seguia para um compromisso de campanha em Guarujá (SP), mobilizou diversos setores da mídia jornalística em uma cobertura que se transformou em espetáculo político-midiático. Após a morte de Campos, o cenário eleitoral tornou-se emblemático diante da possibilidade real de Marina Silva (PSB), que assumiu o lugar de Campos (PSB) na corrida presidencial, derrotar Dilma Rousseff (PT) nas urnas.

Permeada por estratégias agressivas de marketing, a cobertura dos candidatos à presidência do Brasil obteve extensa visibilidade nos veículos de comunicação do país, que atuaram como verdadeiros porta-vozes do discurso político. Nesse sentido, entender como se efetivou a cobertura do escândalo da Petrobras no Jornal Nacional, durante o período da campanha presidencial, é o objetivo deste estudo, que pretende responder como foi representada a imagem da presidente e candidata à reeleição Dilma Rousseff (PT) nas reportagens que retrataram a temática. Como amostra, pretende-se estudar o desdobramento do escândalo político-midiático envolvendo a Petrobras desde a oficialização da campanha, em 6 de julho de 2014, até o fim do segundo turno da eleição presidencial, em 27 de outubro do mesmo ano.

O referencial teórico do enquadramento da mídia será utilizado como aporte para a interpretação das reportagens. Para auxiliar na análise das notícias, optou-se pela perspectiva da análise de conteúdo da pesquisadora Bardin (2011). O procedimento metodológico será detalhado ao longo do artigo.

\section{Escândalo político-midiático e a construção da imagem pública}

O desenvolvimento dos meios de comunicação no decorrer do século XX alterou o ambiente das práticas políticas, principalmente a relação de contato dos líderes com suas bases e a ligação da ação política com os cidadãos. No âmbito das modificações, merece destaque a imbricação constante entre esfera pública e privada, em especial no que se refere às figuras de autoridade e poder.

O espaço midiático tornou-se não apenas o meio, mas o local onde passou a se desenvolver a cena política. A visibilidade trazida pelas mídias alterou toda a noção de publicidade dos acontecimentos políticos. Na mediação dos indivíduos com a esfera política, a mídia assumiu o papel antes relegado aos partidos e se tornou substituta de algumas de suas funções tradicionais, como a fiscalização e o fornecimento de informações das ações governamentais nas diversas instâncias de poder. 
Nesse sentido, merecem atenção os escândalos que engendram no espaço político contemporâneo. Jiménez Sánchez (2004 apud ROSA, 2011, p. 1167) define o escândalo político como "uma intensa reação social de indignação logo que existe um conhecimento público da ocorrência de certo comportamento levado a cabo por um ator desempenhando um cargo público investido com confiança social". Com o surgimento da imprensa, os escândalos políticos assumem uma nova constituição, uma vez que facilmente ganham os holofotes da mídia.

Thompson (2002) debruça-se sobre essa temática, ao elucidar que as formas de abertura de comunicação constituem o modo principal de propagação dos escândalos políticos, que possuem capacidade de se deslocar facilmente do universo local e nacional para acontecimentos com visibilidade global. $\mathrm{O}$ autor descreve tais escândalos como eventos midiáticos, ao identificar que "a apresentação através da mídia, e o comentário na mídia, não são características secundárias ou acidentais dessas formas de escândalos: elas são parte constitutivas deles" (p. 91).

É diante desse universo virtual com vida e leis próprias de funcionamento, no qual se incorporam a imprensa, a propaganda e as demais formas de representação midiática, que são construídas, tal qual elucidou Sodré (2002), as imagens públicas dos personagens políticos. Essas imagens constituem o poder simbólico (BOURDIEU, 1998), um tipo de capital de extrema relevância para o campo, que os agentes políticos lutam constantemente por acumular e preservar. Qualquer ação que afete a imagem dos atores políticos pode incidir na diminuição desse capital.

Nesse sentido, é possível identificar que boa parte das ações dos atores políticos passou a ser captada e difundida pelos meios de comunicação, incidindo de maneira positiva na construção da imagem pública, ao conferir maior visibilidade às suas propostas e realizações sociais. Em contrapartida, o cenário de atuação do político tornou-se mais vulnerável, diante da exposição amplificada da mídia, conferida, primordialmente, a qualquer ato impróprio ou deslize moral.

Um ato de corrupção possui todos os ingredientes para se transformar em escândalo político-midiático, já que transgride os valores morais, ao violar regras e infringir convenções ou leis, mas, sobretudo, pelo interesse dos veículos de comunicação na produção de bens simbólicos que tenham caráter sensacionalista e despertem a atenção do público (THOMPSON, 2002).

Diante dos esforços de qualquer ator político na construção de uma imagem pública de reputação e confiança, os meios, de maneira consciente ou não, se prevalecem da visibilidade midiática e utilizam seu poderio para atuar justamente nas fontes de capital simbólico que estão em disputa quando ocorre um escândalo político. Ainda, atrelados 
a propósitos políticos, os escândalos são eficazes na capacidade de desgastar os capitais simbólicos de reputação e confiança dos envolvidos.

\begin{abstract}
São as manchetes dos jornais, a presença de avaliações negativas na imprensa, as críticas e por vezes as humilhantes caricaturas das pessoas cujas ações (reais ou supostas) são objetos de reprovação: é a apresentação repetida desses atos midiáticos que gera o clima de desaprovação característico dos escândalos midiáticos (Ibidem, p. 97).
\end{abstract}

Apoiadas em sofisticadas tecnologias de comunicação, as informações escandalosas são veiculadas por meio de evidências relativamente duráveis, como filme fotográfico, áudios de gravação, sistemas digitais de informação etc. Tais conteúdos conferem maior veracidade ao acontecimento e inviabilizam a capacidade de negar o ocorrido.

Além disso, a importância de uma evidência fixada em meios duráveis permite que o desenrolar do escândalo seja reproduzido em inúmeras ocasiões e por inúmeros veículos de comunicação, consolidando o processo que Thompson (2002) denominou de "midiatização ampliada", no qual a evidência do escândalo circula de maneira rápida e abrangente, alimentando um processo que, apesar das tentativas de limitar o prejuízo de imagem para os indivíduos envolvidos, pode facilmente fugir do controle.

Na política de imagem, Gomes (2004) aponta que diante da crise de representatividade que os partidos e as lideranças políticas enfrentam no mundo contemporâneo, a participação dos meios de comunicação se torna cada vez mais importante em toda arena da disputa eleitoral - do jogo político à conquista da hegemonia. Ao entender que parte fundamental da virtú dos líderes políticos tem sido frequentemente construída pela mídia por meio de uma poderosa e abrangente coleção de técnicas sociais (IANNI, 2003), a produção de enquadramentos midiáticos tem se convertido em um poderoso instrumento para o controle e a determinação da imagem de indivíduos e instituições participantes da práxis política.

\title{
O enquadramento da mídia: uma metodologia para análise da produção jornalística
}

A primeira sistematização sobre o conceito de enquadramento, denominado "framing analysis", foi realizada por Erving Goffman, em sua obra Frame analysis: na essay on the organization of experience ${ }^{3}$, publicada em 1974. A ideia de enquadramento (frames) derivava da preocupação de Goffman em entender como cada sujeito particular

3 A versão traduzida para o português chegou às livrarias em 2012 sob o título Os quadros da experiência social: uma perspectiva de análise. 
classificava e organizava uma dada situação social e atribuía sentido à realidade a seu redor. Para o autor, "enquadramentos são entendidos como marcos interpretativos mais gerais, construídos socialmente, que permitem às pessoas dar sentido aos eventos e às situações sociais" (1986 apud PORTO, 2004, p. 78).

Durante o período de pesquisa, Goffman atentou para a questão da audiência, com o intuito de verificar como o público recebia e interpretava as informações enquadradas pela mídia. Entretanto, a primeira aplicação do conceito de enquadramento no campo de comunicação foi publicada em 1978 pela socióloga Gaye Tuchman, no livro Making news. A pesquisa buscou demonstrar como o enquadramento de uma informação pode atuar no sentido de reforçar o poder político, auxiliando a construção ou a definição de uma determinada realidade (PORTO, 2004).

Mais adiante, após o surgimento de inúmeros estudos que ampliaram as noções de enquadramento com análises do discurso da mídia nas esferas sociais e políticas, o sociólogo Eatman(1993) propôs uma revisão sistemática do conceito, ao definir que enquadrar envolve seleção e saliência:

Enquadrar é selecionar alguns aspectos de uma realidade percebida e fazê-los mais salientes no texto comunicativo de modo a promover uma definição particular de um problema, interpretação causal, avaliação moral e/ou um tratamento recomendado para o item descrito (Ibidem, p. 52).

Reconhecido como importante instrumento de poder informativo, Porto (2004) aponta que, para mapear os diferentes tipos de enquadramento utilizado nos relatos jornalísticos, é necessário adotar um modelo sistemático de análise que permita maior criticidade na aplicação da metodologia. Com o objetivo de romper com a retórica funcionalista, em que os meios de comunicação se orientam a partir de um enquadramento dominante, ele estabeleceu uma classificação para análise das mensagens televisivas, cuja proposta busca sistematizar a presença ou ausência de mais de um enquadramento nos segmentos do conteúdo da mídia.

Assim, o autor denomina segmento restrito as mensagens que possuem um único enquadramento interpretativo sobre determinado tema político e nomeia de segmentos plurais os que possuem mais de um enquadramento. Os segmentos plurais se dividem em plurais fechados, nos quais é possível identificar certo privilégio ou ênfase a um determinado aspecto da notícia, e plurais abertos, em que nenhum enquadramento é apresentado como válido ou verdadeiro. Os segmentos que adotam forma episódica não incluem enquadramentos interpretativos, adotando um estilo mais descritivo de reportagem (PORTO, 2001). 
O passo seguinte para a correta aplicação metodológica reside na identificação das principais controvérsias e enquadramentos presentes nas notícias, com o intuito de averiguar quais atores sociais distintos possuem capacidade para influenciar o processo de enquadramento, além dos grupos dominantes e influentes, já que é imprescindível, segundo Porto (2004, p. 94), "incluir as interpretações promovidas por movimentos sociais ou de oposição, inclusive aquelas que são excluídas pela mídia”, explicitando, quando possível, "as razões que levam ao predomínio de certos enquadramentos, em detrimento de outros".

Por fim, a definição de uma análise sistemática de conteúdo aparece como item fundamental para identificar as práticas de enquadramento. Independente do método adotado, Porto (2001) alerta para a importância de eleger um enfoque integrado que inclua uma análise de conteúdo quantitativa e uma análise textual de teor qualitativo.

$\mathrm{Na}$ aplicação do método ao conteúdo jornalístico do Jornal Nacional, foram selecionadas apenas as matérias com enquadramento interpretativo, a fim de entender a seleção e a ênfase atribuída pelas reportagens ao retratar o escândalo da Petrobras e a relação com a presidente e candidata à reeleição Dilma Rousseff (PT), durante o período de campanha eleitoral.

Para compreender o conteúdo veiculado pela narrativa jornalística, recorreu-se à análise de conteúdo (BARDIN, 2011) e às três etapas que compõem essa metodologia. Na primeira etapa, foi realizada a seleção das reportagens que serviram como objeto do estudo. Nesse caso, foram privilegiadas apenas as matérias que retrataram o escândalo da Petrobras. Após a visualização do conteúdo jornalístico, na segunda, as unidades de análise foram agrupadas, com base nos formatos episódico, restrito, plural aberto e plural fechado. Na terceira e última etapa, os resultados obtidos foram interpretados e comparados à luz do contexto político e do cenário eleitoral.

\section{O enquadramento do escândalo da Petrobras no Jornal Nacional}

O escândalo da Petrobras alcançou visibilidade midiática com a investigação de um esquema de lavagem de dinheiro que teria movimentado ilegalmente 10 bilhões de reais. Denunciado em março de 2014, o esquema, nomeado de operação Lava Jato pela Polícia Federal, era chefiado por Paulo Roberto Costa, que atuou como diretor de Abastecimento e Refino da Petrobras, de 2006 a 2012.

O esquema abrangia inúmeros atos de corrupção, como o desvio de recursos da estatal para intermediar negócios com fornecedores, por meio de recolhimento e pagamento

\footnotetext{
$48 \frac{\text { Comunicação \& Inovação, PPGCOM/USCS }}{\text { v. 16, n. } 32 \text { (41-58) set-dez } 2015}$
} 
de propina da ordem de milhões de reais e repasses de verbas à base aliada do governo e partidos políticos, sobretudo em períodos de campanhas eleitorais. A transação financeira era comandada pelo doleiro Alberto Youssef, acusado de organizar o esquema bilionário de lavagem de dinheiro, cuja função era gerenciar os recursos para que chegassem aos políticos de diversas legendas partidárias, entre as quais se destacam o Partido dos Trabalhadores (PT), o Partido do Movimento Democrático Brasileiro (PMBD) e o Partido Progressista (PP), todos mencionados pela mídia no decorrer das denúncias.

Presos pela Polícia Federal, Paulo Roberto Costa e Alberto Youssef concordaram em realizar um acordo de delação premiada, em agosto e setembro de 2014, com o intuito de atenuar a pena. Os depoimentos dos acusados realizados na esfera do Ministério Público e da Polícia Federal ocorreram sob sigilo jurídico. Entretanto, o escândalo político alcançou maior repercussão quando os áudios dos depoimentos de Alberto Yousseff e Paulo Roberto, com trechos das denúncias, vazaram na mídia.

No centro do escândalo político, a presidente Dilma Rousseff (PT) era também acusada de favorecer, por meio de um parecer falho, a aquisição da refinaria de Pasadena nos Estados Unidos, que acarretou um prejuízo da ordem de US\$ 792 milhões para a Petrobras e foi aprovada em 2006, no período em que a candidata à reeleição presidia o Conselho Administrativo e atuava como ministra da Casa Civil do governo Lula (PT). Na lista dos desacertos, o não cumprimento do acordo firmado em 2005, entre o ex-presidente da Venezuela Hugo Chaves e o ex-presidente do Brasil Luiz Inácio Lula da Silva (PT), para a construção da refinaria Abreu e Lima, em Pernambuco, obrigou a Petrobras a bancar sozinha o investimento de mais de U\$S 18 bilhões, quando a parceria estabelecia que o Brasil garantiria $60 \%$ da refinaria, enquanto a petroleira venezuelana PDVSA ficaria com $40 \%$.

Nesse cenário, as denúncias de corrupção envolvendo a Petrobras fomentavam diariamente a agenda dos noticiários, sobretudo durante o período de campanha eleitoral. A pesquisa realizada pelo Laboratório de Estudos de Mídia e Esfera Pública (LEMEP) ${ }^{4}$ apontou maior incidência na divulgação do escândalo político da Petrobras pelos jornais Folha de S. Paulo, O Globo, O Estado de S. Paulo e Jornal Nacional, durante o período da oficialização da campanha. O estudo contabilizou um total de 249 reportagens vinculadas ao escândalo da Petrobras, no período de 6 de julho até 25 de outubro de 2014.

Durante o período oficial de campanha, o Jornal Nacional divulgou 53 reportagens sobre a Petrobras, conforme aponta a Tabela 1.

4 O LEMEP é sediado no Instituto de Estudos Sociais e Políticos (IESP) da Universidade do Estado do Rio de Janeiro (UERJ). Disponível em: <http://www.manchetometro.com.br/analises/escandalos/>. Acesso em: 3 jan. 2014 
Tabela 1: Reportagens do Jornal Nacional - Escândalo Petrobras (6 julho a 27 outubro)

\begin{tabular}{|c|c|c|}
\hline Data & Título & Enquadramento \\
\hline 16 de jul. & CPI da Petrobras aprova quebra do sigilo de doleiro e de ex-diretor & Episódico \\
\hline 23 de jul. & TCU inocenta Dilma Rousseff de prejuízo com refinaria de Pasadena & Restrito \\
\hline 25 de jul. & Doleiro Youssef passa mal na prisão e está em observação em UTI & Episódico \\
\hline 26 de jul. & Youssef retorna para carceragem da PF, após suspeita de infarto & Episódico \\
\hline 2 de ago. & $\begin{array}{l}\text { Gravação revela que investigados na CPI da Petrobras podem ter ficado } \\
\text { sabendo de perguntas que seriam feitas }\end{array}$ & Plural fechado \\
\hline 4 de ago. & CPI da Petrobras vai investigar denúncia de vazamento de perguntas & Plural fechado \\
\hline 11 de ago. & Contadora de doleiro revela à PF suposto suborno no governo do MA & Plural fechado \\
\hline 20 de ago. & Presidente e ex-diretor da Petrobras doaram imóveis após escândalo & Plural aberto \\
\hline 22 de ago. & PF cumpre mandados em empresas ligadas a Paulo Roberto Costa & Episódico \\
\hline 27 de ago. & TCU adia decisão sobre Foster por prejuízo com refinaria de Pasadena & Episódico \\
\hline 3 de set. & Ex-diretor da Petrobras começa depoimentos da delação premiada & Episódico \\
\hline 5 de set. & Ex-diretor da Petrobras depõe sobre esquema de lavagem de dinheiro & Restrito \\
\hline 6 de set. & $\begin{array}{l}\text { Ex-diretor da Petrobras citou políticos que teriam recebido propina, diz } \\
\text { revista }\end{array}$ & Plural fechado \\
\hline 8 de set. & Presidente de CPI pede o depoimento de ex-diretor da Petrobras completo & Plural fechado \\
\hline 8 de set. & Denúncias de corrupção derrubam ações da Petrobras & Episódico \\
\hline 8 de set. & PF investiga vazamento de depoimento de ex-diretor da Petrobras & Episódico \\
\hline 9 de set. & Oposição quer novo depoimento de Paulo Roberto Costa no Congresso & Restrito \\
\hline 10 de set. & TCU investiga negócios da Petrobras com três refinarias & Restrito \\
\hline 11 de set. & CPI aguarda decisão do STF sobre depoimento de ex-diretor da Petrobras & Episódico \\
\hline 12 de set. & Senado arquiva processo sobre vazamento na CPI da Petrobras & Plural aberto \\
\hline 15 de set. & Justiça decide soltar advogado preso na Operação Lava Jato & Episódico \\
\hline 15 de set. & Justiça autoriza que Paulo Roberto Costa preste depoimento à CPI & Restrito \\
\hline 16 de set. & Depoimento de Paulo Roberto Costa na CPI da Petrobras gera expectativa & Restrito \\
\hline 17 de set. & Ex-diretor da Petrobras repete 18 vezes que não tinha nada a declarar & Plural fechado \\
\hline 18 de set. & Paulo Roberto Costa diz que recebeu R $\$ 1,5$ milhão em compra de refinaria & Restrito \\
\hline 19 de set. & Oposição reage à revelação de Paulo Roberto Costa sobre propina & Restrito \\
\hline 20 de set. & Lava Jato: investigado fala sobre ligação de políticos com doleiro & Plural fechado \\
\hline 22 de set. & Justiça nega acesso da CPI ao depoimento do ex-diretor da Petrobras & Plural fechado \\
\hline 23 de set. & Doleiro Youssef quer acordo de delação premiada & Episódico \\
\hline 24 de set. & Doleiro Youssef assina com o MP acordo de delação premiada & Plural aberto \\
\hline 25 de set. & CPI mista da Petrobras só volta a se reunir depois do $1^{\circ}$ turno da eleição & Episódico \\
\hline 26 de set. & Ex-diretor da Petrobras conclui depoimentos para o Ministério Público & Restrito \\
\hline 29 de set. & Advogado investigado na operação Lava Jato depõe na Justiça Federal & Restrito \\
\hline 30 de set. & Ministro do STF valida delação premiada de ex-diretor da Petrobras & Restrito \\
\hline 1 de out. & Ex-diretor da Petrobras está em prisão domiciliar no Rio de Janeiro & Restrito \\
\hline 2 de out. & Alberto Youssef começa a ser ouvido após delação premiada & Episódico \\
\hline 2 de out. & Cinco parentes de Paulo Roberto Costa fecham acordo de delação & Episódico \\
\hline 3 de out. & Laudo da PF afirma que empresas de Youssef receberam quase R\$ $38 \mathrm{mi}$ & Plural fechado \\
\hline 6 de out. & Imprensa estrangeira destaca as eleições no Brasil & Episódico \\
\hline 8 de out. & Ex-contadora de Youssef diz que emitiu R\$ 7 milhões em notas frias & Plural aberto \\
\hline 8 de out. & Paulo Roberto teria revelado que esquema financiou campanha de 2010 & Restrito \\
\hline
\end{tabular}


Os reveses do escândalo político-midiático nas eleições presidenciais de 2014

\begin{tabular}{|c|l|c|}
\hline \multicolumn{1}{|c|}{ Daf́a } & Tílo & Plural fechado \\
\hline 9 de out. & Paulo Roberto e Alberto Youssef citam PT, PMDB e PP em depoimentos & Restrito \\
\hline 10 de out. & Paulo Roberto e Youssef deram detalhes de esquema na Petrobras & Plural aberto \\
\hline 10 de out. & Delações de Paulo Roberto e Youssef provocam reações de candidatos & Plural fechado \\
\hline 11 de out. & Paulo Roberto Costa revela detalhes de esquema de propina na Petrobras & Plural fechado \\
\hline 13 de out. & Empreiteiras devem explicar pagamentos a empresas de Youssef & Restrito \\
\hline 14 de out. & Juízes federais apoiam colega que apura escândalo da Petrobras & Restrito \\
\hline 15 de out. & TCU analisa irregularidades em obra bilionária da Petrobras & Restrito \\
\hline 17 de out. & Ex-diretor da Petrobras inclui tucano entre os que receberam propina & Restrito \\
\hline 22 de out. & Comissão de Valores Mobiliários abre investigação sobre a Petrobras & Episódico \\
\hline 25 de out. & Doleiro Alberto Youssef é internado em UTI após passar mal em cela & Episódico \\
\hline 27 de out. & Petrobras contrata empresas para apurar ações relatadas por ex-diretor & Episódico \\
\hline 27 de out. & CPI mista da Petrobras cancela depoimento de Alberto Youssef & \\
\hline
\end{tabular}

Na primeira classificação, de teor quantitativo, verifica-se a predominância de 17 enquadramentos com formato episódico. A característica principal do enquadramento episódico é a ausência de entrevistas ou reportagens externas, uma vez que geralmente as notícias são lidas pelos apresentadores do telejornal, em formato de notas.

O formato restrito apareceu em maior quantidade, com 18 reportagens em que se privilegiou apenas um enquadramento interpretativo sobre o escândalo da Petrobras, ao lado de 12 matérias veiculadas no formato plural fechado. As matérias com formato plural fechado comportaram maior número de entrevistas, em que prevaleceu mais de um enquadramento sobre o escândalo, porém com maior ênfase e destaque para fontes de oposição ao governo. O formato plural aberto reuniu cinco reportagens, com matérias que comportaram mais de um enquadramento, com espaço compatível do noticiário ocupado por entrevistas da base governista, dos membros da Comissão Parlamentar de Inquérito (CPI) do Senado e Mista, líderes da oposição e políticos citados nas denúncias.

Para realizar a análise interpretativa das reportagens veiculadas pelo Jornal Nacional, optou-se por selecionar a quantidade de uma a duas matérias, nos formatos restrito, plural fechado e plural aberto, veiculadas nos meses de agosto, setembro e outubro, momento em que o escândalo obteve maior repercussão na mídia. Tal medida foi adotada diante da impossibilidade de analisar todas as reportagens, em função da extensão que o artigo ganharia.

De maneira semelhante, apesar de apresentar um número significativo de chamadas, a análise das notícias com formato episódico foi desconsiderada, já que se trata de um formato em que geralmente o conteúdo jornalístico é exibido de maneira breve e descritiva, conforme indica a nota "CPI da Petrobras aprova quebra do sigilo de doleiro e de ex-diretor", publicada no dia 16 de julho, em que a apresentadora Patrícia Poeta faz referência à quebra de sigilo bancário do ex-doleiro Alberto Youssef e do ex-diretor da Petrobras, Paulo Roberto Costa. 
Já o enquadramento restrito ficou demarcado por notícias que deram ao escândalo da Petrobras, na voz da oposição e da revista Veja, maior visibilidade, atuando, por vezes, como fontes exclusivas das matérias. Para exemplificar, a reportagem com a chamada "Oposição quer novo depoimento de Paulo Roberto Costa no Congresso", veiculada no dia 9 de setembro, apontava a pressão da oposição para que o presidente da CPI no Senado, Vital do Rego (PMDB), convocasse um novo depoimento do ex-diretor de abastecimento da Petrobras, Paulo Roberto Costa.

Segundo a matéria, o senador Vital do Rego (PMDB), que preside a CPI da Petrobras no Senado, não havia se pronunciado sobre os dados da reportagem da revista Veja com revelações de Paulo Roberto Costa sobre um esquema de corrupção ocorrido durante os governos Lula e Dilma. Entre as denúncias exibidas pelo noticiário, o apresentador do Jornal Nacional, William Bonner, apontava que o ex-diretor indicou para a Polícia Federal um esquema de pagamento de propina e de caixa paralelo para financiar partidos aliados do governo, que envolvia três governadores, um ministro, pelo menos 25 deputados federais e seis senadores - parlamentares do PT, PMDB e PP. A reportagem do Jornal Nacional não mencionou que os dados da revista Veja eram baseados em fontes extraoficiais, uma vez que os depoimentos de Paulo Roberto Costa à Polícia Federal ocorreram sob sigilo da justiça.

Ainda sem mencionar a fidedignidade da fonte, o Jornal Nacional revelou na matéria "Paulo Roberto Costa diz que recebeu R \$ 1,5 milhão em compra de refinaria", exibida no dia 18 de setembro, trechos do depoimento em que Paulo Roberto Costa apontou um esquema de corrupção na compra da refinaria de Pasadena, nos Estados Unidos, em que ele recebeu R \$ 1,5 milhão para favorecer a transação. Para conferir maior veracidade ao escândalo político-midiático, um trecho do depoimento em que Paulo Roberto Costa aponta o financiamento das campanhas de partidos políticos, referenciando em especial o PT e a base aliada do governo, obteve destaque na reportagem "Paulo Roberto e Youssef deram detalhes de esquema na Petrobras" exibido pelo Jornal Nacional do dia 10 de outubro, conforme segue:

Voz em off: Paulo Roberto contou que 3\% do valor dos contratos eram desviados. Um por cento ia para o PP, e 2\% para o PT. Mas que, no caso do Partido dos Trabalhadores, havia também pagamentos exclusivos.

Paulo Roberto Costa: Então se tinha PT na diretoria de Exploração e Produção. PT na diretoria de Gás e Energia e PT na área de serviços. O comentário que pautava lá dentro da companhia é que neste caso os $3 \%$ ficavam diretamente para o PT $(\mathrm{G} 1,2014)$. 
Nas reportagens com enquadramento restrito ${ }^{5}$, o escândalo da Petrobras foi agendado com ênfase e destaque para as denúncias de corrupção, com base em depoimentos e vazamentos de áudios e textos, além de entrevistas com líderes da oposição, sem qualquer espaço para vozes dissonantes. Nesse sentido, ao privilegiar o maior número de reportagens de formato restrito, o Jornal Nacional contribuiu para a formação de um enquadramento dominante sobre o escândalo da Petrobras, construído pela voz da oposição e dos delatores do esquema de corrupção, como a revista Veja e outros veículos de comunicação.

As reportagens com enquadramento plural fechado, de maneira semelhante, obtiveram como fonte dados extraoficiais da revista Veja, em que as interlocuções da oposição e da Comissão Parlamentar Mista de Inquérito (CPMI) dispuseram de maior visibilidade, em detrimento de entrevistas com aliados da base governista e aqueles mencionados nas denúncias, que por inúmeras vezes foram retratadas ao fim das reportagens, com esclarecimentos lidos pelos apresentadores William Bonner ou Patrícia Poeta. Para exemplificar esse tipo de enquadramento, a reportagem veiculada em 9 de outubro, com a chamada "Paulo Roberto e Alberto Youssef citam PT, PMDB e PP em depoimentos", exibiu trechos dos depoimentos de Paulo Roberto Costa e de Alberto Youssef, concedidos à Polícia Federal, com relatos sobre os envolvidos no esquema de corrupção.

Entre as denúncias exibidas no vídeo, prevaleceu parte dos depoimentos em que os delatores citaram o esquema de corrupção envolvendo políticos e os partidos PT, PMDB e PP. Entre as revelações, o ex-diretor indicou que existia um cartel na Petrobras, formado em 2006, durante o governo do ex-presidente Lula. Ao alternar áudios e entrevistas, a reportagem deu ênfase às supostas declarações de Youssef e de Paulo Roberto Costa, em que eles apontam a participação de 13 empreiteiras no esquema, entre elas Camargo Corrêa, Odebrecht, OAS, Queiroz Galvão, Andrade Gutierrez e Mendes Júnior.

Os relatos dos depoentes indicaram que a aprovação da compra da Usina de Pasadena envolveu transações ilícitas, com pagamento de propinas, entre outras irregularidades de desvio de verbas vinculadas à petrolífera. A resposta dos citados no escândalo, por outro lado, ocupou um espaço restrito no final da matéria, com breves considerações sobre o tema, lidas por William Bonner, conforme indica o trecho citado em mais duas reportagens de formato plural fechado: "O Palácio do Planalto e o ex-presidente Lula declararam que não vão se manifestar sobre o assunto".

A revista Veja foi usada como fonte para quatro das reportagens com enquadramento plural fechado. A matéria com o título "Gravação revela que investigados na CPI

5 A pesquisa não identificou reportagens de enquadramento restrito em agosto de 2014. 
da Petrobras podem ter ficado sabendo de perguntas que seriam feitas", exibida em 2 de agosto, apontava, com base em denúncias da revista, que os investigados do esquema de corrupção da Petrobras, o ex-diretor da estatal, Nestor Cerveró, e a atual presidente Graça Foster, ouvidos em 21 de maio de 2014, na CPI do Senado, receberam as perguntas com antecedência e foram treinados para respondê-las. Ao veicular prioritariamente os dados da revista e a suposta gravação do chefe do escritório da Petrobras em Brasília, alertando para o esquema, a reportagem do Jornal Nacional não conferiu a veracidade da fonte, retransmitindo na íntegra dados da revista que apontavam o governo e a liderança do PT no Senado como autores de uma fraude.

Ainda embasada em dados da revista Veja, a reportagem exibida no dia 4 de agosto, com a chamada "CPI da Petrobras vai investigar denúncia de vazamento de perguntas", reafirmou os depoimentos divulgados no dia 2 de agosto, com a inserção da entrevista do relator da CPI da Petrobras, senador Vital do Rêgo (PMDB/PB), que anunciou a formação de comissão para investigar a denúncia publicada pelo periódico. Durante a matéria, foi concedido um espaço para que os candidatos à presidência comentassem as denúncias. Nesses comentários, o candidato Eduardo Campos (PSB) lançou críticas diretas ao governo federal, fomentando o discurso de mudança.

No dia 8 de setembro, a revista Veja foi mencionada na reportagem "PF investiga vazamento de depoimento de ex-diretor da Petrobras". A matéria apontava as investigações da Polícia Federal em torno dos vazamentos dos depoimentos e, na sequência, exibia novas denúncias publicadas pela revista, indicando o tesoureiro do PT, João Vaccari Neto, como o operador encarregado de fazer a ponte entre a Petrobras e as empreiteiras que contribuíam para um caixa paralelo de partidos e políticos governistas.

Entre os entrevistados, o discurso de Rubens Bueno (PPS), líder do partido da oposição no Congresso, endossava a necessidade de investigar os esquemas de corrupção para que a Petrobras não seguisse como alvo de um aparelhamento, acabando por favorecer partidos e parlamentares. Como voz dissonante, a matéria trazia apenas a entrevista do deputado Marco Maia (PT), relator da CPMI, que indicava a necessidade de cautela nas acusações, por se tratar de denúncias importantes, que demandavam as respectivas provas e relatórios produzidos pela Polícia Federal.

Na matéria intitulada, "Ex-diretor da Petrobras repete 18 vezes que não tinha nada a declarar", veiculada no dia 17 de setembro, o Jornal Nacional aponta que Paulo Roberto Costa, preso na Operação Lava-Jato da Polícia Federal, repetiu 18 vezes que não tinha nada a declarar no depoimento realizado à CPMI. A reportagem retoma o depoimento concedido por ele à Polícia Federal e ao Ministério Público, publicado pela revista Veja, em que ele indicava a participação de três governadores, um ministro e pelo menos 25 
deputados federais e seis senadores, parlamentares do PT, PMDB e PP, partidos da base aliada do governo, nos desvios de dinheiro da Petrobras.

Nesse sentido, ainda que as reportagens com formato plural fechado comportassem mais de um enquadramento, a ênfase dada ao escândalo da Petrobras privilegiou a voz da oposição, uma vez que tanto a CPMI de investigação quanto os citados nas denúncias obtiveram espaço restrito, por vezes com respostas às acusações narrada pelos âncoras do telejornal. Portanto, ao conceder espaço reduzido para membros do governo e para os indivíduos citados nas denúncias, o Jornal Nacional manteve um enquadramento predominante sobre o tema, em consonância com o formato restrito.

Por fim, as matérias com formato plural aberto ocuparam espaço reduzido no Jornal Nacional e foram marcadas por reportagens em que foi possível identificar um equilíbrio entre as denúncias de corrupção, as entrevistas da oposição e da CPMI e os mencionados no escândalo. Como exemplo, tem-se a reportagem "Senado arquiva processo sobre vazamento na CPI da Petrobras", veiculada no dia 12 de setembro. A matéria relata que após realizar sindicância, o Senado resolveu arquivar o processo de vazamento da CPI da Petrobras, por não haver indício de garantias e informações privilegiadas, de documentos internos da comissão ou de resumos de questionamentos que seriam formulados aos depoentes.

A reportagem reafirmou que as informações partiram da revista Veja e concedeu espaço uniforme para o presidente da CPI, Vital do Rêgo (PMDB), que apontou a ausência de irregularidades nos depoimentos, ao lado das críticas da oposição, veiculadas por Rodrigo Maia (DEM), que se mostrou indignado com o resultado das investigações da CPI do Senado.

De maneira semelhante, a matéria "Presidente e ex-diretor da Petrobras doaram imóveis após escândalo", exibida em 20 de agosto, informava que o Tribunal de Contas da União havia suspendido a discussão sobre o possível bloqueio dos bens da presidente da Petrobras, Graça Foster, e do diretor da área internacional da estatal, Nestor Cerveró. Investigados pela Polícia Federal na transação que envolveu a compra da refinaria de Pasadena, a reportagem apontava que os acusados efetuaram movimentação de parte do patrimônio, doando os imóveis para familiares próximos um dia antes da presidente Dilma Rousseff (PT) dizer que apoiou a compra da refinaria de Pasadena, quando era presidente do Conselho de Administração da Petrobras, por causa de um "parecer falho" elaborado por Nestor Cerveró.

De maneira equânime, a reportagem veiculou a entrevista do advogado-geral da União, Luís Inácio Adams, que apontou não ter identificado irregularidades no ato, uma vez que as doações dos imóveis, por usufruto, não seriam tentativas de esconder patrimônio, como também concedeu espaço para o relator do processo, José Jorge, ministro do 
Tribunal de Contas da União (TCU), que alegou que as doações de imóveis configuram atos graves e, se comprovadas, podem caracterizar uma burla ao processo de apurações de irregularidades.

Já a reportagem "Delações de Paulo Roberto e Youssef provocam reações de candidatos", veiculada em 10 de outubro, exibiu a opinião dos candidatos que disputavam o segundo turno das eleições à presidência, Dilma Rousseff (PT) e Aécio Neves (PSDB), a respeito dos depoimentos de Paulo Roberto Costa e Alberto Youssef. Na entrevista concedida ao noticiário, Dilma Rousseff (PT) foi incisiva ao alertar que o país foi surpreendido com gravações de depoimentos à Justiça de dois indivíduos presos pela Polícia Federal.

A candidata indicou que era muito estranho e estarrecedor que no meio de uma campanha eleitoral viesse à tona esse tipo de divulgação, de maneira leviana e incompleta, em pleno período eleitoral. Já o candidato Aécio Neves (PSDB) indicou a necessidade de aprofundar as investigações e reafirmou que, se fosse eleito presidente do Brasil, todos os responsáveis seriam processados e punidos. O discurso de Dilma Rousseff (PT) trouxe indicativos de que a mídia atuou para fomentar as denúncias de corrupção da Petrobras, justamente em um momento decisivo da campanha eleitoral, quando se buscava a reeleição. Entretanto, ainda que imputando um viés tendencioso aos veículos de comunicação, a reportagem do Jornal Nacional exibiu a entrevista da candidata petista.

A quantidade limitada de reportagens no formato plural aberto, em que as vozes da oposição e dos envolvidos nos escândalos obtiveram espaço equânime, serve com base para reafirmar que o $J N$ priorizou um enquadramento predominante sobre o tema.

\section{Breves considerações: o escândalo da Petrobras e a imagem de Dilma Rousseff (PT) no Jornal Nacional}

O escândalo político-midiático da Petrobras envolveu aliados da base governista, outros partidos e políticos em denúncias de fraudes e esquemas de corrupção. As reportagens veiculadas pela mídia associavam, ainda que indiretamente, Dilma Rousseff (PT) ao escândalo, mesmo que não existisse prova da participação da presidente nos atos ilícitos.

Durante o período analisado, o Jornal Nacional publicou nove reportagens nas quais relatou que o esquema de cartel e pagamento de propina funcionou na Petrobras entre o período de 2006 a 2012, nos governos Lula e Dilma. A repetição, no referido telejornal, do tumulto criado em torno da corrupção na Petrobras, como ensina Thompson (2002), impactou negativamente na campanha à reeleição da candidata pelo PT.

Ao mencionar que os desvios de verba na Petrobras se encerraram em 2012, com a saída de Paulo Roberto Costa, as reportagens do Jornal Nacional associavam ainda que 
indiretamente a gestão de Dilma Rousseff (PT) ao esquema, ao afirmar que os atos de corrupção finalizaram somente no segundo ano do seu primeiro mandato presidencial. Além disso, como candidata à reeleição pelo PT, a imagem de Dilma Rousseff ficou enfraquecida diante das acusações realizadas contra o partido e políticos associados à legenda.

Outro dano à imagem da candidata Dilma Rousseff (PT) esteve ligado às denúncias de que parte do dinheiro desviado da Petrobras serviu para financiar as campanhas eleitorais de 2010, ocasião em que a presidente petista disputou seu primeiro mandato. Apesar de não indicar claramente que a campanha de Dilma Rousseff (PT) foi beneficiada, a reportagem do Jornal Nacional mencionou que os delatores Paulo Roberto Costa e Alberto Youssef citaram o PT, o PMDB e o PP entre os partidos favorecidos pelo esquema.

Para evidenciar ainda mais o quanto um escândalo de tal magnitude é capaz de desmoronar a imagem de um indivíduo público, vale a comparação das notícias selecionadas do Jornal Nacional com outras variáveis do cenário eleitoral, no caso, pesquisas de intenção de voto no primeiro turno. Importante ressaltar a equivalência de mídias envolvidas. A pesquisa de intenção de voto no primeiro turno para presidente, realizada pelo Datafolha e TV Globo, mostrava Dilma Rousseff com 38\% no dia 2 de julho. Conforme as reportagens sobre o caso se sucediam, a intenção de voto em Dilma diminuía, chegando a 36\% em 18 de agosto (UOL ELEIÇÕES, 2014).

A reviravolta no cenário eleitoral veio com a morte de Eduardo Campos, como já mencionado, e com a substituição deste pela vice-candidata Marina Silva. Com a popularidade em baixa, a concorrente pelo PT chegou 35\% das intenções de voto, enquanto Marina Silva subia até chegar a 34\%. Esse cenário manteve-se estável enquanto durou a comoção pela morte de Eduardo Campos.

No dia 10 de setembro, o Jornal Nacional noticiou "TCU investiga negócios da Petrobras com três refinarias", uma delas era justamente a Abreu e Lima, em Pernambuco, em cujos negócios o ex-governador supostamente estaria envolvido. No dia 20 de setembro, o telejornal trouxe a manchete "Lava Jato: investigado fala sobre ligação de políticos com doleiro", enfatizando a ligação de Eduardo Campos no esquema.

Nesse período, o cenário de intenções de votos começava a se modificar. Dilma subia nas pesquisas e Marina caia. Em 26 de setembro, a candidata do PT chegou a 40\% da intenção de voto e Marina 27\%. Dilma se manteria estável até 4 de outubro, enquanto Marina chegaria a 22\%. A vitória apertada de Dilma Rousseff (PT) no segundo turno, com uma margem de aproximadamente $2 \%$ em relação a seu opositor, o candidato Aécio Neves (PSDB), traz indicativos do impacto do escândalo político durante a campanha presidencial.

Assim, este estudo teve como pretensão mostrar a força de um escândalo político-midiático, sobretudo em períodos eleitorais. A ocasião aflora os interesses de políticos 
experientes, neopolíticos e da mídia, mediadora das disputas. No caso analisado, foi possível constatar como as notícias da mídia, em especial do $J N$, contribuíram para enfraquecer a imagem de Dilma Rousseff (PT) e, consequentemente, seu capital simbólico ao longo da disputa eleitoral.

\section{Referências}

BARDIN, L. Análise de conteúdo. Lisboa: Edições 70, 2011.

BOURDIEU, P. O poder simbólico. Rio de Janeiro: Bertrand Brasil, 1998.

DATAFOLHA. Com 36\%, Dilma lidera após início oficial da campanha eleitoral. São Paulo, 18 jul. 2014. Disponível em: <http://datafolha.folha.uol.com.br/eleicoes/2014/07/1487860-com-36-dilma-lidera-apos-inicio-oficial-da-campanha-eleitoral.shtml>. Acesso em: 4 nov. 2015.

ENTMAN, R. M. Framing: toward clarification of a fractured paradigm.Journalof Communication, v. 43, n. 4, p. 51-58, 1993.

FOLHA DE S. PAULO. Popularidade de Dilma cai 27 pontos após protestos. Caderno Poder, 29 jun. 2013. Disponível em: <http://www1.folha.uol.com.br/poder/2013/06/1303541-popularidade-de-dilma-cai-27-pontos-apos-protestos.shtml>. Acesso em: 3 nov. 2015.

G1. Costa diz em delação premiada que recebeu propina de R\$ 1,5 milhão. 18 set. 2015. Disponível em: $<$ http://g1.globo.com/politica/noticia/2014/09/costa-diz-em-delacao-premiada-que-recebeu-propina-de-r-15-milhao.html>. Acesso em: 4 nov. 2015.

GOMES, W. Transformações da política na era da comunicação de massa. São Paulo: Paulus, 2004.

IANNI, O. O príncipe eletrônico. In: DOWBOR, L. et al. (Orgs.). Desafios da comunicação. 2. ed. Petrópolis: Vozes, 2003.

PORTO, M. Media framing and citizen competence: television and audience's interpretation of politics in Brazil. Tese (Doutorado) - University of California, San Diego, 2001. . Enquadramentos da mídia e política. In: RUBIM, A. A. C. (Org.). Comunicação e política: conceitos e abordagens. Salvador: UFBA, 2004.

ROSA, A. M. O conceito de escândalo: entre a realidade midiática e a realidade antropológica. In: VII CONGRESSO SOPCOM. 2001. Anais...Porto: Universidade do Porto, 2001.

SODRÉ, M. Existe consciência ética na imprensa? In: PAIVA, R. Ética, cidadania e imprensa. Rio de Janeiro: Mauad, 2002.

THOMPSON, J. B. O escândalo político: poder e visibilidade na era da mídia. Petrópolis: Vozes, 2002.

UOL ELEIÇÕES. Intenção de voto no $1^{\circ}$ turno para presidente. 4 out. 2014. Disponível em: <http://eleicoes.uol.com.br/2014/pesquisas-eleitorais/brasil/1-turno/>. Acesso em: 4 nov. 2015. 